\title{
Commentary
}

\section{Controlled traction-a key for safe laparoscopic cholecystectomy}

\author{
Mallikarjuna Manangi ${ }^{1}$, Dharini Dharini ${ }^{2}$, Tanvi Sunil Kumar ${ }^{1}$, Ramya M. Vishweshwara ${ }^{1 *}$
}

${ }^{1}$ Department of General Surgery, Bangalore Medical College and Research Institute, Bangalore, Karnataka, India

${ }^{2}$ Department of Plastic and Reconstructive Surgery, Vardhaman Mahaveer Medical College, New Delhi, India

Received: 08 November 2020

Revised: 12 January 2021

Accepted: 15 January 2021

\section{*Correspondence:}

Dr. Ramya M. Vishweshwara,

E-mail: romidocmpl@gmail.com

Copyright: (c) the author(s), publisher and licensee Medip Academy. This is an open-access article distributed under the terms of the Creative Commons Attribution Non-Commercial License, which permits unrestricted non-commercial use, distribution, and reproduction in any medium, provided the original work is properly cited.

\begin{abstract}
Laparoscopic cholecystectomy (LC) is one of the most common laparoscopic procedures performed. The technique of LC has witnessed numerous modifications according to surgeon's preferences to improve the ergonomics, surgical ease, safety and outcome. Dissection of the gall bladder from the liver bed is one of the troublesome steps. We aim to describe a unique method which is technically easy to perform and provides excellent exposure as well. A total of 206 patients underwent laparoscopic cholecystectomy at our Institute over a year from January 2017 to 2018 . The technique of torquing the gallbladder to dissect it off its bed is surgeon friendly with advantages of instrumentation and visualization.
\end{abstract}

Keywords: Laparoscopic cholecystectomy, Technique, Dissection from liver bed, Safe Cholecystectomy

\section{INTRODUCTION}

Semm, in 1980, performed the first successful laparoscopic surgery to perform an appendicectomy. ${ }^{1}$ In 1985, Eric Muhe performed the first laparoscopic cholecystectomy. ${ }^{2}$ Laparoscopic cholecystectomy is one of the surgeries which propelled the laparoscopic era into the highly evolved field that it is now. In 1992, the national institute of health declared that the gold standard for treatment of symptomatic cholelithiasis is laparoscopic cholecystectomy. ${ }^{3}$

The laparoscopic cholecystectomy technique has seen numerous changes over the decades. Each surgeon titrates the surgical technique to suit personal preference.

One of the troublesome steps of laparoscopic cholecystectomy is dissection of the gall bladder from the liver bed. We describe a unique method which is easy to perform at the same time gives excellent exposure.

\section{STANDARD PROCEDURE}

The patient is placed supine on the operating table with the surgeon standing at the patient's left side. The pneumoperitoneum is created with carbon dioxide gas, either with an open technique or by closed needle technique. The laparoscope with the attached video camera is passed through the umbilical port and the abdomen inspected. Three additional ports are placed under direct vision. A $10-\mathrm{mm}$ port is placed in the epigastrium, a 5-mm port in the middle of the clavicular line, and a 5-mm port in the right flank, in line with the gallbladder fundus. Through the lateral-most port, a grasper is used to grasp the gallbladder fundus. It is retracted over the liver edge upward and towards the patient's right shoulder to expose the proximal gallbladder and the hilar area. Exposure of the hilar area may be facilitated by placing the patient in reverse Trendelenburg position with slight tilting of the table to bring the right side up. Through the midclavicular port a second grasper is used to grasp the gallbladder infundibulum and retract it laterally to expose the triangle of Calot. Most of the dissection is carried out through the 
epigastric port using a dissector, hook cautery, or scissors. The dissection starts at the junction of the gallbladder and the cystic duct. A helpful anatomic landmark is the cystic artery lymph node. The peritoneum, fat, and loose areolar tissue around the gallbladder and the cystic duct-gallbladder junction is dissected off toward the bile duct. This is continued until the gallbladder neck and the proximal cystic duct are clearly identified. The next step is the identification of the cystic artery, which usually runs parallel to and somewhat behind the cystic duct. A hemo clip is placed on the proximal cystic duct. The cystic artery is then clipped and divided. ${ }^{4,5}$

Separation of the gallbladder away from its hepatic bed is then initiated using an electrosurgical probe to coagulate small vessels and lymphatics. By maintaining cephalad traction on the fundus of the gallbladder with the lateral most forceps, the midclavicular forceps pulls the neck of the gallbladder antero-superiorly and then alternatively medially and laterally to expose and place the tissue connecting the gallbladder to its fossa under tension. An electrocautery spatula or hook is used to coagulate and divide the tissue. Intermittent blunt dissection will facilitate exposure of the proper plane. Dissection of the gallbladder fossa continues from the infundibulum to the fundus, progressively moving the midclavicular grasping forceps cephalad to allow maximum counter traction. The dissection proceeds until the gallbladder is attached by only a thin bridge of tissue. Before the gallbladder is removed from the liver edge, the operative field is carefully searched for bleeding points, and the placement of the clips on the cystic duct and cystic artery is inspected. The gallbladder is removed through the umbilical incision. If the gallbladder was severely inflamed or gangrenous or if any bile or blood is expected to accumulate, a closed-suction drain can be placed through one of the 5-mm ports and left underneath the right liver lobe close to the gallbladder fossa.

\section{HOW WE DO IT DIFFERENTLY}

The standard procedure is followed up to the step of clipping and dividing of the cystic duct and cystic artery. The lateral-most grasper is used to maintain cephalad traction to the fundus of the gallbladder. The grasper through the midclavicular line port is used to grasp the neck of the gallbladder. Utilizing the ratchet of the grasper, the gallbladder neck is held firmly. The knob of the grasper is rotated to produce a continuous, progressive torquing force on the gallbladder, in a direction away from the bed, so as to provide traction to allow dissection of the gallbladder from its bed using standard cautery hook or harmonic scalpel. This dissection is continued till the entire gallbladder is dissected off the bed. The surgery is then proceeded with as per standard procedure.

The advantages of this method include ease of dissection as the traction provided is adequate. It prevents frequent changing of the graspers' grip of tissue as the dissection can be completed by just a single application of the grasper to the neck of the gallbladder. The visualization obtained by this technique is also superior as the parts of the gallbladder which have already been dissected off do not obstruct the view, and the bed with bridge of tissue connecting it to the gallbladder yet to be dissected off the bed, can be directly visualized.

The technique must be used in carefully selected patients. The torquing force applied should be gradually increased, with care being taken so as to not rupture the gallbladder, especially in distended gallbladders.

\section{RESULTS}

A total of 206 patients underwent laparoscopic cholecystectomy at Bangalore medical college and research institute over a year from January 2017 to 2018 .

None of the patients developed any surgery related complications.

\section{Advantages}

The torque force when applied at the fundus of the gall bladder, force gets transmitted to the part which is still adherent to the liver, since it is fixed at that point. Adherent part of the bladder gets pulled away from the liver bed at the same time, by pushing the instrument caudally, liver also gets lifted up providing an excellent view.

Rolling the gall bladder on itself provides uniform and controlled exertion of tractional force at the adherent part. This minimizes the pulling and pushing which is otherwise required with two instruments.

Since there is uniform traction, complications like liver capsular tear, subcapsular hematoma and also iatrogenic perforation of the gall bladder is prevented.

Figures 1 to 3 represents the step of dissection of gall bladder from the liver bed.

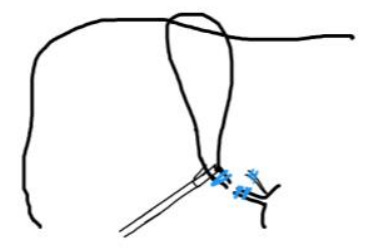

Figure 1: The step of clipping of cystic duct and artery. 


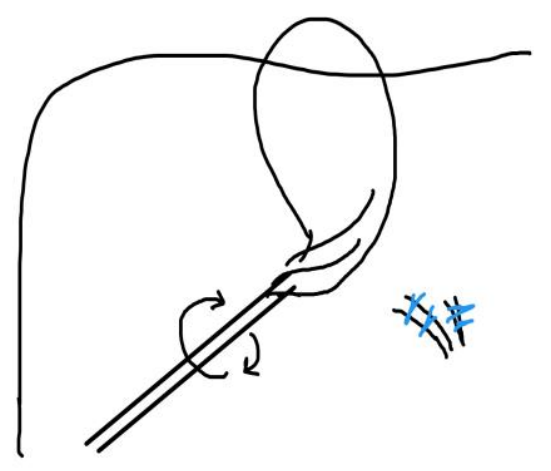

Figure 2: The step of torquing force.

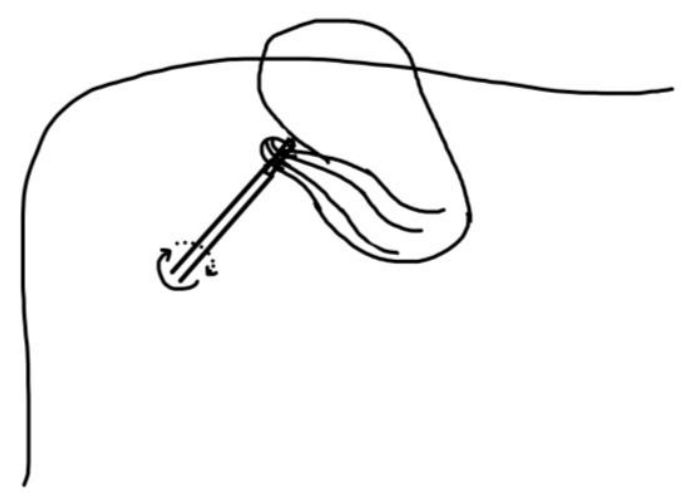

Figure 3: The step of dissection of gall bladder from the liver bed.

\section{CONCLUSION}

This technique of torquing the gallbladder to dissect it off its bed is surgeon friendly with advantages of instrumentation and visualization.

Funding: No funding sources

Conflict of interest: None declared

Ethical approval: Not required

\section{REFERENCES}

1. Lityanski GS. Kurt Semm and the fight against skepticism: Endoscopic haemostasis, laparoscopic appendectomy and Semm's impact on the 'laparoscopic revolution' JSLS. 1998;2:309-13.

2. Littnski GS. Highlights in the History of Laparoscopy. Frankfurt, Germany: Barbara Berneret Verla. 1996:165-8.

3. NIH Consensus conference. Gallstones and laparoscopic cholecystectomy. JAMA. 1993;269:1018-24.

4. Pham TH, Hunter JG. Gall bladder and Biliary System In: Brunicardi FC, Anderson DK, Billiar TR, Dunn DL, Hunter JG, Matthews JB et al editors. Schwartz's Principles of Surgery. $10^{\text {th }}$ ed. Mc Graw Hill Education. 2015.

5. Auyong ED, Soper NJ. Cholecystitis and Cholelithiasis in: Zinner MJ, Ashley SW, editors. Maingot's Abdominal Operations. $12^{\text {th }}$ ed. Mc Graw Hill Medical. 2013.

Cite this article as: Manangi M, Dharini D, Kumar TS, Vishweshwara RM. Controlled traction-a key for safe laparoscopic cholecystectomy. Int Surg J 2021;8:773-5. 